\title{
Amiodarone-Induced Thyrotoxicosis with Thyroid Papillary Cancer in Multinodular Goiter: Case Report
}

\author{
Hidefumi Inaba ${ }^{a, c}$ Satoru Suzuki ${ }^{a}$ Teiji Takeda ${ }^{a}$ Satoshi Kobayashi ${ }^{b}$ \\ Takashi Akamizuc Mitsuhisa Komatsu ${ }^{\mathrm{c}}$ \\ Departments of a Aging Medicine and Geriatrics and ${ }^{b}$ Gastroenterogy, Shinshu University School of Medicine, \\ Matsumoto, and ${ }^{\mathrm{C} F i r s t}$ Department of Medicine, Wakayama Medical University, Wakayama, Japan
}

\section{Key Words}

Amiodarone $\cdot$ Thyrotoxicosis $\cdot$ Thyroid cancer •

Multinodular goiter

\begin{abstract}
Objective: To report a case of amiodarone-induced thyrotoxicosis (AIT) concomitant with thyroid cancer in multinodular goiter (MNG). Clinical Presentation and Intervention: A 61-year-old man treated with amiodarone for 5 years presented with mild sweating. He was found to have AIT simultaneously with thyroid papillary cancer and MNG. Administration of amiodarone was stopped, and he was treated with methimazole for AIT. Five weeks after the initial treatment, thyroid function normalized. Total thyroidectomy was considered to enable use of amiodarone again. Conclusion: This case showed that thyrotoxicosis, MNG and amiodarone may contribute to thyroid carcinogenesis. Amiodarone should be carefully commenced in cases with MNG.
\end{abstract}

Copyright $\odot 2011$ S. Karger AG, Basel

\section{Introduction}

Amiodarone is an antiarrhythmic drug that is widely used all over the world. Hyperthyroidism appears in $1-23 \%$ of patients treated with amiodarone [1]. Type I amiodarone-induced thyrotoxicosis (AIT) is characterized by excessive synthesis and secretion of thyroid hormone, whereas type II AIT is due to a destructive mechanism acting on thyrocytes [1]. Although two cases of type II AIT with thyroid papillary cancer have been reported $[2,3]$, no case of type I AIT with thyroid carcinoma has been reported.

Hyperthyroidism was not thought to be associated with thyroid cancer. However, recently Taneri et al. [4] reported that hyperthyroidism is positively related to the incidence of thyroid cancer. Pathological investigations suggest that multinodular goiter (MNG) potentially initiates thyroid cancer [5]. Moreover, carcinogenic activity of amiodarone has been also reported in various tissues $[6,7]$.

We herein report a case of AIT concomitant with thyroid papillary cancer in MNG.

\section{Case Report}

A 61-year-old man was admitted to our hospital because of thyrotoxicosis. His chief complaint was mild sweating. He lived in an iodine-sufficient area. He did not have any previous radiation exposure. Five years before admission, he was admitted to our hospital for percutaneous transluminal coronary angioplasty as treatment for acute myocardial infarction. He eventually suffered from ventricular tachycardia. Treatment with $5 \mathrm{mg}$ /day

\section{KARGER}

Fax +4161306 1234 E-Mail karger@karger.ch www.karger.com (c) 2011 S. Karger AG, Basel

1011-7571/12/0212-0190\$38.00/0

Accessible online at:

www.karger.com/mpp
Hidefumi Inaba

Department of Aging Medicine and Geriatrics

Shinshu University School of Medicine

3-1-1, Asahi, Matsumoto, 390-8621 (Japan)

Tel. +81 263372 686, E-Mail inabaaa2000@yahoo.co.jp 


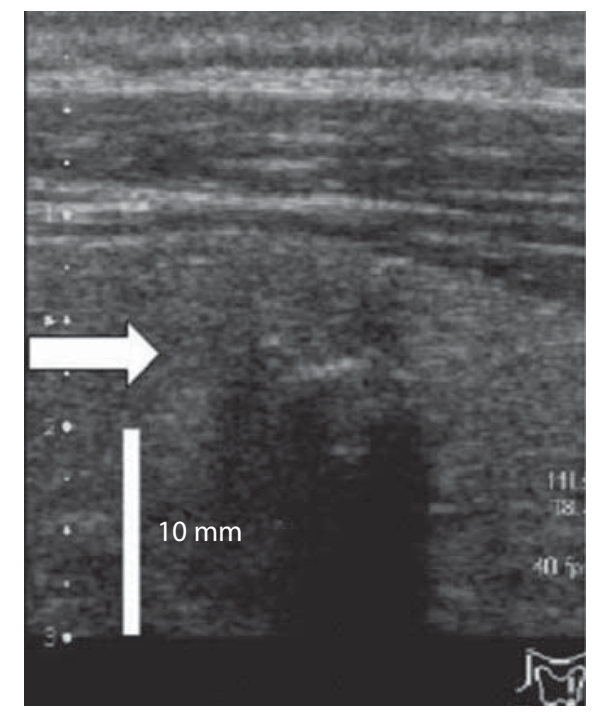

Fig. 1. Cervical ultrasonography. In the left upper lobe, a 7-mm echoic lesion with an irregular margin and unclear border (arrow) and small calcifications were observed.

of enalapril, $10 \mathrm{mg} /$ day of carvedilol, and $200 \mathrm{mg} /$ day of amiodarone was commenced. Simultaneously, a cardioverter defibrillator was implanted. Thyroid palpation was not recognized, and cervical ultrasonography had not been performed in previous visits.

Upon admission, the patient had the following characteristics: height $164 \mathrm{~cm}$, body weight $52 \mathrm{~kg}$, body temperature $37.0^{\circ} \mathrm{C}$, blood pressure $108 / 75 \mathrm{~mm} \mathrm{Hg}$, and heart rate 60 beats/min. The thyroid gland was palpable. Finger tremor was not observed. The signs of Möbius/Graefe were negative.

The results of laboratory examinations upon admission are shown in table 1 . Thyrotoxicosis was recognized since the serum concentration of thyrotropin (TSH) was $<0.005 \mu \mathrm{IU} / \mathrm{ml}$ (normal range $0.23-4.0$ ), free triiodothyronine (fT3) was $4.76 \mathrm{pg} / \mathrm{ml}$ (normal range 2.3-4.0), and free thyroxine (fT4) was $3.45 \mathrm{ng} / \mathrm{dl}$ (normal range 1.0-2.0). Anti-thyroglubulin, anti-thyroid peroxidase, and anti-TSH receptor antibodies were negative.

Cervical utrasonography showed a slightly enlarged thyroid gland (weight $20.6 \mathrm{~g}$ ). Multinodular lesions were detected in both thyroid lobes. In the left upper lobe, a 7-mm lesion with low echogenicity and small calcifications were observed (fig. 1). The Doppler flow rate inside of the thyroid gland was not decreased. Consequently, fine needle aspiration biopsy of the lesion was performed (fig. 2). Intranuclear inclusion bodies, nuclear grooves, atypical nuclei, and an increased N/C rate were observed. Colloid was present. Thus, the lesion was diagnosed as thyroid papillary cancer. The clinical disease grade was defined as pT1.

Thyrotoxicosis developed within 58 months of the initiation of amiodarone (fig. 3). The patient was diagnosed as possibly type I (or type II) AIT with thyroid papillary cancer and MNG. Amiodarone was discontinued and treatment with $30 \mathrm{mg} /$ day of methimazole (MMI) was initiated (59 months in fig. 3) [1]. Two weeks after therapy with MMI, thyroid function gradually

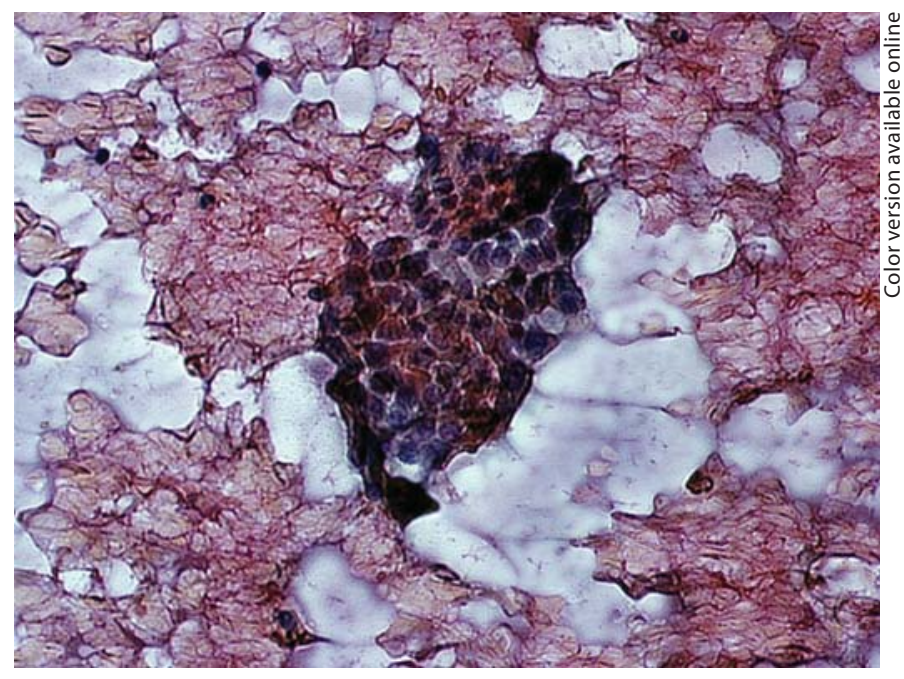

Fig. 2. Fine needle aspiration cytology biopsy of the low-echoic lesion was performed (Papanicolaou staining, $\times 100$ ). A high N/C ratio, intranuclear inclusion bodies, nuclear grooves, nuclear atypia, mitotic alteration, and colloid were observed.

Table 1. Laboratory tests and endocrinological findings on admission

\begin{tabular}{llll}
\hline $\mathrm{WBC} / \mathrm{mm}^{3}$ & 5,740 & $\mathrm{Na}, \mathrm{mEq} / \mathrm{l}$ & 135 \\
$\mathrm{Hb}, \mathrm{g} / \mathrm{dl}$ & 13.2 & $\mathrm{~K}, \mathrm{mEq} / \mathrm{l}$ & 4.3 \\
$\mathrm{Plt} / \mathrm{mm}^{3}$ & $21.9 \times 10^{4}$ & $\mathrm{Cl}, \mathrm{mEq} / \mathrm{l}$ & 99 \\
$\mathrm{TP}, \mathrm{g} / \mathrm{dl}$ & 7.1 & $\mathrm{CRP}, \mathrm{mg} / \mathrm{dl}$ & 0.29 \\
$\mathrm{Alb}, \mathrm{g} / \mathrm{dl}$ & 3.6 & $\mathrm{TSH}, \mu \mathrm{IU} / \mathrm{ml}$ & $<0.005^{\mathrm{a}}$ \\
$\mathrm{BUN}, \mathrm{mg} / \mathrm{dl}$ & 15 & $\mathrm{fT} 3, \mathrm{pg} / \mathrm{ml}$ & $4.76(2.3-4.0)^{\mathrm{a}}$ \\
$\mathrm{Cr}, \mathrm{mg} / \mathrm{dl}$ & 1.08 & $\mathrm{fT} 4, \mathrm{ng} / \mathrm{dl}$ & $3.45(1.0-2.0)^{\mathrm{a}}$ \\
$\mathrm{AST}, \mathrm{IU} / \mathrm{l}$ & $52(12-37)^{\mathrm{a}}$ & $\mathrm{Tg}, \mathrm{ng} / \mathrm{dl}$ & $84.4(<78)^{\mathrm{a}}$ \\
ALT, IU/l & $67(7-45)^{\mathrm{a}}$ & TgAb & - \\
ALP, IU/l & $240^{\mathrm{a}}$ & TPOAb & - \\
$\gamma-\mathrm{GTP}, \mathrm{IU} / \mathrm{l}$ & $52(8-50)^{\mathrm{a}}$ & TRAb & $6.4 \%(<10 \%)$ \\
T-bil, mg/dl & 0.39 & TSAb & $151 \%(<180 \%)$ \\
\end{tabular}

$\mathrm{Tg}=$ Thyroglobulin; $\mathrm{TgAb}=$ anti-thyroglobulin antibody; $\mathrm{TPOAb}=$ anti-thyroid peroxidase antibody; TRAb = anti-TSH receptor antibody; TSAb = thyroid-stimulating antibody.

a Abnormal values.

improved. Five weeks after the initial treatment, thyroid function normalized, and MMI was withdrawn. Thereafter, the patient was given levothyroxine sodium to suppress secretion of TSH as treatment for thyroid cancer (65 months in fig. 3). Cardiac function did not worsen after discontinuation of amiodarone but was still deteriorated. Total thyroidectomy was considered, to enable the use of amiodarone again with careful observation. 


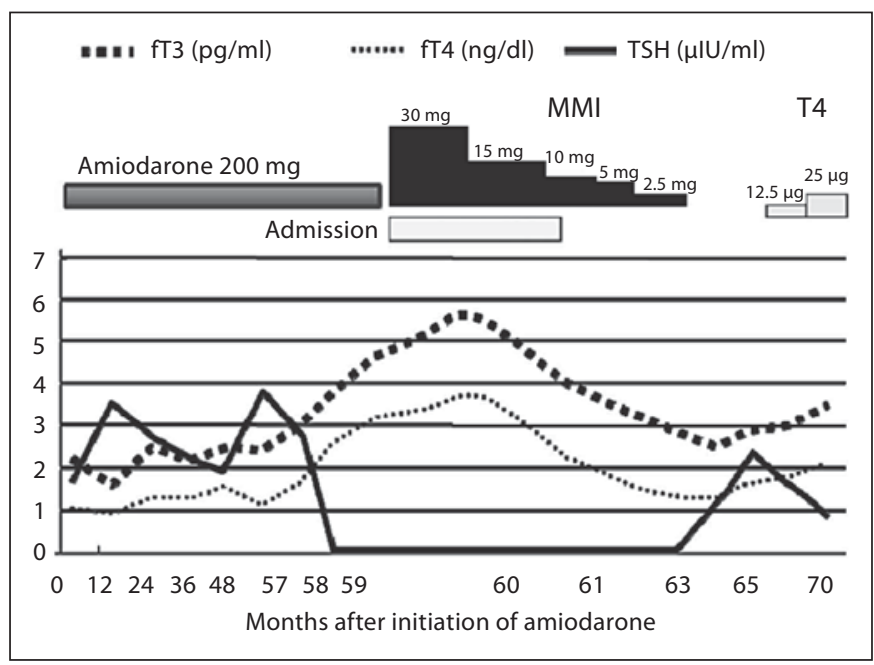

Fig. 3. Clinical course. Upon the diagnosis of AIT, treatment with MMI (30 mg/day) was commenced (59 months). Two weeks later, thyroid function improved. Five weeks later, thyroid function was normalized. Administration of levothyroxine sodium was started to suppress TSH secretion (65 months).

\section{Discussion}

In this case, the existence of thyrotoxicosis after the initial treatment with amiodarone, nonsuppressed blood flow and an enlarged thyroid gland seen on ultrasonography, an almost normal value of serum thyroglobulin, and an effective response to MMI supported the diagnosis of type I AIT [1]. Moreover, it is known that type I AIT can occur in association with MNG. However, the possibility of type II AIT was not completely excluded because neither radioactive iodide uptake scintigram nor serum IL- 6 values were obtained.
Recent investigation indicates that hyperthyroidism is positively related to the development of thyroid cancer. Taneri et al. [4]. reported that the incidence of thyroid carcinoma with Graves' disease is 3-8\%; however, it increases to $15 \%$ if the patient also has a thyroid nodule. Mori et al. [5] reported that the presence of MNG increased the risk of thyroid cancer and concluded that MNG may be a premalignant lesion. These reports imply that hyperthyroidism may contribute to the growth of thyroid cancer in the current case.

It is known that the incidence of thyroid cancer is significantly increased in rats with amiodarone [6]. Amiodarone induces photosensitivity and pigmentation with ultraviolet waves [6] and is associated with basal cell carcinoma [7]. With administration of amiodarone, radiation toxicity may be amplified in the skin and thyroid gland [8]. Taken together, radiation or ultraviolet waves may enhance the carcinogenic activity in amiodarone.

On the basis of cellular biology, amiodarone has been thought to damage thyrocytes [9]. Pitsiavas et al. [9] reported that amiodarone induced distortion of thyroid construction, necrosis, apoptosis, and abnormality in endoplasmic reticulum. Cell damage or apoptosis has also been observed in other organs such as the liver and lung [10]. These pathological findings indicate that amiodarone may initiate thyroid cancer or cause it to progress.

\section{Conclusion}

This case showed that hyperthyroidism, MNG, and amiodarone may contribute to thyroid carcinogenesis. Amiodarone should be carefully commenced in cases with MNG.

\section{References}

-1 Harjai KJ, Licata AA: Effects of amiodarone on thyroid function. Ann Intern Med 1997; 126:63-73.

-2 Saad A, Falciglia M, Steward DL, Nikiforov YE: Amiodarone-induced thyrotoxicosis and thyroid cancer: clinical, immunohistochemical, and molecular genetic studies of a case and review of the literature. Arch Pathol Lab Med 2004;128:807-810.

$\checkmark 3$ Cattaneo F: Type II amiodarone-induced thyrotoxicosis and concomitant papillary cancer of the thyroid. Eur J Endocrinol 2000; 143:823-824.
4 Taneri F, Kurukahvecioglu O, Ege B, Yilmaz U, Tekin EH, Cifter C, Onuk E: Clinical presentation and treatment of hyperthyroidism associated with thyroid cancer. Endocr Regul 2005;39:91-96.

5 Mori I, Miyauchi A, Kuma S, Tang W, Kakudo K: Thyroid nodular lesion: analysis of cancer risk based on Kuma Hospital experience. Pathol Int 2003;53:579-583.

6 Medication Guide, Amiodarone $\mathrm{HCl}, \mathrm{NDA}$ 18-972/S-038/039, US Food and Drug Administration, 2004.

$\checkmark 7 \mathrm{Maoz} \mathrm{KB}$, Dvash S, Brenner S, Brenner S: Amiodarone-induced skin pigmentation and multiple basal-cell carcinomas. Int J Dermatol 2009;48:1398-1400.
8 Bridges AB, Davies RR, Newton RW, McNeill GP: Anaplastic carcinoma of the thyroid in a patient receiving radioiodine therapy for amiodarone-induced thyrotoxicosis. Scott Med J 1989;34:471-472.

-9 Pitsiavas V, Smerdely P, Li M, Boyages SC: Amiodarone induces a different pattern of ultrastructural change in the thyroid to iodine excess alone in both the $\mathrm{BB} / \mathrm{W}$ rat and the Wistar rat. Eur J Endocrinol 1997;137: 89-98.

10 Vassallo P, Trohman RG: Prescribing amiodarone: an evidence-based review of clinical indications. JAMA 2007;298:1312-1322. 